and cost of community service provision. London: Department of Epidemiology and Public Health, Imperial College School of Medicine at St Mary', 1997.

- The lifetime costs of care for a child infected with HIV have been estimated at $£ 178300$

- Screening pregnant women for HIV can avert this cost and lead to gains in life years for both mothers and children

- Universal, voluntary antenatal HIV screening is estimated to be a cost effective intervention with cost saving potential in areas in which there is a high prevalence of HIV infection among pregnant women

- In areas with lower prevalence rates, cost effectiveness could be well below $£ 20000$ per life year gained, and universal, voluntary antenatal screening could be considered

lence rates. These conclusions confirm the recent recommendations of the Intercollegiate Working Party for Enhancing Voluntary Confidential HIV Screening in Pregnancy. ${ }^{27}$

The authors thank Jeni Beecham, Margaret Brandeau, Miranda Mugford, Marie-Louise Newell, Angus Nicoll, Tony Oliver, Doug Owens, and Richard Smith, as well as our referees for their invaluable assistance at various stages of the study.

Contributors: MJP and EJB conceived the idea for the project. MJP developed the cost effectiveness model in conjunction with EJB, SM, LS, MDSW, HH, and JCJ. EJB and SM provided the cost data that were used in the model. LS provided particular input on the social context. MDSW provided specific input on the clinical context relevant to the analyses as well as providing clinical care to many of the children who participated in the original study. MJP and EJB were primarily responsible for writing the paper; the paper was written in conjunction with SM, LS, MDSW, HH, and JCJ. MJP and EJB are guarantors of the study.

Funding: European Union Concerted Action on Multinational AIDS Scenarios (contract No BMH1-CT94-1723).

Competing interests: None declared.

1 Mercy D. Antenatal HIV screening. BMJ 1998;316:241-2.

2 Dunn DT, Newell ML, Ades AE, Peckham CS. Risk of human immunodeficiency virus type 1 transmission through breastfeeding. Lancet 1992:340:585-8.

3 European collaborative study. Caesarean section and risk of vertical transmission of HIV-1 infection. Lancet 1994;343:1464-7.

4 Connor EM, Sperling RS, Gelber R, Kiselev P, Scott G, O'Sullivan MJ, et al. Reduction of maternal-infant transmission of human immunodeficiency virus type 1 with zidovudine treatment. $N$ Engl J Med 1994:331:1173-80.

5 Beck EJ, Mandalia S, Griffith R, Walters MDS, Levin M, Boulton M, et al. The hospital and community services study of families with HIV infection: initial analyses of hospital service provision and costs for HIV-infected children St Mary's Hospital, 1986-1994. London: Department of Epidemiology and Public Health, Imperial College School of Medicine at St Mary's, 1997.

6 Beck EJ, Griffith R, Mandalia S, Beecham J, Boulton M, Walters MDS, et al. The hospital and community services study of families with HIV infection: use
7 Centers for Disease Control. Classification system for human immunodeficiency virus (HIV) infection in children under 13 years of age. MMWR Morb Mortal Wkly Rep 1987;36:225-31.

8 NHS Executive. Hospital and community health services revenue (pay and prices) inflation index. Leeds: NHS Executive Finance and Performance Department A, 1997

9 Jefferson T, Demicheli V, Mugford M. Elementary economic evaluation in health care. London: BMJ Publishing Group, 1996.

10 Gibb DM, MacDonagh SE, Tookey PA, Duong T, Nicoll A, Goldberg D, et al. Uptake of interventions to reduce mother-to-child transmission of HIV in the United Kingdom and Ireland. AIDS 1997;11:F53-8.

11 Royal College of Obstetricians and Gynaecologists. National study of HIV in pregnancy. London: RCOG, 1997. (Newsletter 31.)

12 Mugford M. How does the method of cost estimation affect the assessment of costeffectiveness in health care [DPhil thesis]. Oxford: University of Oxford, 1996.

13 Chrystie IL, Zander L, Tilzey A, Wolfe CDA, Kenny A, Banatvala JE. Is HIV screening in pregnancy worthwhile: can we afford it? AIDS Care $1995 ; 7: 135-42$.

14 Savage-King F. Breast feeding programmes and HIV questions. Geneva: Marathon Multimedia, Cicero, 1998. [Abstract No 310.]

15 Parsonage M, Neuberger H. Discounting of health benefits. Health Economics 1992;1:71-6.

16 Beck EJ, Pozniak A, Molesworth A, Power A, Griffin J, Easterbrook P, et al. Changing cost of English HIV service provision, 1996-1997. Int J STD AIDS (In press).

17 Nicoll A, McGarrigle C, Brady ARG, Ades AE, Tookey P, Duong T, et al. Epidemiology and detection of HIV-1 among pregnant women in the United Kingdom: results from national surveillance. BMJ 1998; 316:253-8.

18 Jordan R, Law M. An appraisal of the efficacy and cost-effectiveness of antenatal screening for hepatitis B. J Med Screen 1997;3:117-27.

19 Boer R, de Koning H, Threlfall A, Warmerdam P, Street A, Friedman A, et al. Cost effectiveness of shortening screening interval or extending age range of NHS breast screening programme: computer simulation study. BMJ 1998;317:376-9.

20 Laupacis A, Feeny D, Detsky AS, Tugwell PX. How attractive does a new technology have to be to warrant adoption and utilization? Tentative guidelines for using clinical and economic evaluations. Can Med Assoc J 1992;146:473-81.

21 Owens DK. Interpretation of cost-effectiveness analyses. J Gen Intern Med 1998;13:716-7.

22 AIDS from maternally transmitted HIV Infection. J Med Screening 1997;4:177.

23 Centers for Disease Control. Public Health Service task force recommendations for the use of antiretroviral drugs in pregnant women infected with HIV-1 for maternal health and for reducing perinatal HIV-1 transmission in the United States. MMWR Morb Mortal Wkly Rep 1998; 47(RR-2):1-30.

24 Wade N, Birkhead GS, Warren BL, Charbonneau TT, French PT, Wang L, et al. Abbreviated regimens of zidovudine prophylaxis and perinatal transmission of the human immunodeficiency virus. $N$ Engl J Med 1998;339:1409-14.

25 McIntosh K. Short (and shorter) courses of zidovudine. N Engl J Med 1998;339:1467-8.

26 Mandelbrot L, Le Chenadec J, Berrebi A, Bongam A, Béniflor JL, Delfraissy JL, et al. Perinatal HIV-1 transmission: interaction between zidovudine prophylaxis and mode of delivery in the French perinatal cohort. JAMA 1998;280:55-60.

27 Intercollegiate Working Party for Enhancing Voluntary Confidential HIV Screening in Pregnancy. Reducing mother-to-child transmission of HIV infection in the UK. London: Royal College of Paediatrics and Child Health, 1998.

(Accepted 24 February 1998)

\title{
Antenatal HIV testing: assessment of a routine voluntary approach
}

Wendy M Simpson, Frank D Johnstone, David J Goldberg, Siobhan M Gormley, Graham J Hart

Papers pp 1650,

1656

Correspondence to:

Dr W M Simpson,

22 Lumsden Park,

Cupar, Fife KY15

$5 \mathrm{YL}$

wendy@lumsdenpark.

freeserve.co.uk

continued over

BMJ 1999;318:1660-1
The benefits of testing pregnant women for HIV are increasingly assured, particularly with regard to reducing vertical transmission. ${ }^{1}$ Yet uptake of antenatal HIV testing in Britain remains low. ${ }^{2}$ Our previous study examined an opt-in approach (women had to make an active choice to be tested). ${ }^{3}$ Some women were uncomfortable with this, feeling that it indicated high risk behaviour. We therefore assessed an approach based on similar requirements for information and consent but with a change in emphasis, in that testing was routine unless the woman declined.

\section{Subjects, methods, and results}

The testing programme was conducted during February to April 1998. Before their booking appointment, all women were sent a leaflet about blood tests to be conducted, including HIV testing. At the antenatal 
Comparison of uptake rates and anxiety among women offered HIV testing through different approaches in the same hospital's antenatal clinic

\begin{tabular}{lccc} 
Approach & Time period & $\begin{array}{c}\text { No of women having test/No of women } \\
\text { attending clinic (\% uptake) }\end{array}$ & Scaled mean anxiety \\
\hline Control $^{*}$ & May 1996 to Feb 1997 & $55 / 994(6)$ & $36.8(10.8)$ \\
\hline Opt-in† & May 1996 to Feb 1997 & $707 / 2030(35) \S$ & $36.4(10.9)$ \\
\hline Routine voluntary $\ddagger$ & Feb to May 1998 & $816 / 924(88)$ & $33.2(10.6)$ \\
\hline Significance & & $\chi^{2}=1413.6, \mathrm{df}=2, \mathrm{P}<0.0001$ & $\mathrm{~F}(2,3448)=32.3, \mathrm{P}<0.0001$
\end{tabular}

${ }^{*}$ Test available on request only.

†Information given about testing and woman asked to choose whether she wanted test.

fInformation given about testing, but with testing presented as part of routine testing of blood and women given the opportunity to decline the test.

$\S$ Combined result for four different levels of an opt-in approach, which did not result in significantly different uptake rates. ${ }^{3}$

ๆScores out of 24 have been scaled with a denominator of 80 to be comparable to the original 20 item anxiety scale used in previous study. ${ }^{3}$

clinic they were offered an HIV test by midwives who had been trained to use a printed discussion protocol that emphasised the benefits and presented the test as routine, making it clear that the woman could decline. As with the other blood tests, consent was given orally. The midwives noted uptake, time taken to discuss the test, and whether the woman or her partner was at risk of HIV from injecting drug use (this used to be the main local source of HIV transmission, although sexual transmission now predominates ${ }^{4}$ ). Women were then asked to complete a questionnaire measuring attitudes, satisfaction, anxiety, ${ }^{5}$ knowledge about the test, and reasons for agreeing to or declining the test. Key outcomes were compared with those observed in the same setting during 1996-7.'

Of the 924 women who booked at the clinic, 816 $(88.3 \%)$ had an HIV test; one woman not at high risk was found to be HIV positive. One woman was already known to be HIV positive and was not tested. The prevalence of HIV positivity was therefore 2/817 $(0.2 \%)$. The mean time taken to offer the test was 2 minutes 34 seconds (range 1-15 minutes). One of the eight women at high risk because of injecting drug use declined to be tested.

The questionnaire response rate was $99.1 \%$ (916/924). Most women (793/904 (87.7\%)) answered yes to the question, "Do you think the HIV test should be a routine test like all the other blood tests during pregnancy (i.e. it's done unless you say you don't want it)?" The mean anxiety score was 33.2 (SD 10.6; maximum possible 80 ). A question about reducing vertical transmission with zidovudine elicited a correct response by $69 \%$ of women $(628 / 905)$. The most frequent reasons given for declining the test were, "Not necessary as I've no chance of being positive" $(n=28)$ and "I've been in a stable relationship for a long time" $(n=15)$.

\section{Comment}

The uptake of the HIV test (88\%) in this study is more than double the rate (35\%) achieved in the 1996-7 opt-in study ${ }^{3}$ (table). During the year between the two studies, the attitude of women and midwives to HIV testing may have changed owing to increasing knowledge about effective treatment and considerable media exposure. Yet despite these possible changes, the magnitude of the increase in uptake suggests that this approach is more effective than an opt-in approach, and those who decline testing do not seem to be doing so because of high risk status. Moreover, this approach was not time consuming, required no extra staff, and was positively endorsed by most women. Compared with women in the opt-in study, the women were significantly less anxious and more knowledgeable about the protective effects of zidovudine; there was no evidence that women found it difficult to decline a est.

We cannot conclude that this approach will achieve a similar outcome in London, where there are more complex issues of language and cultural heterogeneity. But provided that safeguards are in place to ensure that women can make a fully informed choice, our routine voluntary approach is in keeping with recent guidelines $^{1}$ and may be acceptable and appropriate in other clinics in high prevalence areas.

We thank especially Barbara Hamilton for the database management and clerical support. We are also grateful to the antenatal clinic midwives, the auxiliaries, the medical records staff, and the pregnant women who took the time to participate in the study.

Contributors: WMS designed, developed, and coordinated the study, carried out the data analysis, and interpreted the data. FDJ, the principal investigator, designed the study, and had input into development, data analysis, and interpretation. DJG designed the study and was involved throughout in study supervision and data interpretation. SG supervised the recruitment of pregnant women at the antenatal clinic, the questionnaire returns, and the recording of information by the midwives and helped with data collection. GJH designed the study and was involved throughout in study supervision and data interpretation. WMS wrote the paper jointly with FDJ, with input from the other authors. WMS and FDJ are guarantors for the paper.

Funding: NHS Research and Development Health Technology Assessment Programme.

Competing interests: None declared.

1 Intercollegiate Working Party for Enhancing Voluntary Confidential HIV Testing in Pregnancy. Reducing mother to child transmission of HIV infection in the UK. London: Royal College of Paediatrics and Child Health, 1998

2 Nicoll A, McGarrigle C, Brady AR, Ades AE, Tookey P, Duong T, et al. Epidemiology and detection of HIV-1 among pregnant women in the United Kingdom: results from national surveillance 1988-96. BMJ 1998;316:253-8.

3 Simpson WM, Johnstone FD, Boyd FM, Hart GJ, Goldberg DJ, Prescot RJ. Uptake and acceptability of HIV testing: a randomised controlled trial of different methods of offering the test. BMJ 1998;316:262-7.

4 Johnstone F, Goldberg D, Tappin D, Mathie L, Cameron S, Brown A, et al The incidence and prevalence of HIV infection among childbearing women living in Edinburgh city, 1982-1995. AIDS 1998;12:911-8.

5 Marteau TM, Bekker H. The development of a six-item short-form of the state scale of the Spielberger state-trait anxiety inventory (STAI). Br J Clin Psych 1992;31:301-6.

(Accepted 23 October 1998)

\section{Endpiece Unimpressed}

My life is a constant fight against Doctors' follies, it seems to me.

Virginia Woolf to Violet Dickinson, 26 November 1904

Submitted by Ann Dally, Wellcome Institute for the History of Medicine
Department of Obstetrics and Gynaecology, Centre for

Reproductive Biology, University of Edinburgh, Edinburgh

EH3 9EW

Wendy M Simpson, research psychologist

Frank D Johnstone, consultant obstetrician and senior lecturer

Siobhan Gormley, research midwife

Scottish Centre for Infection and Environmental Health, Clifton

House, Glasgow

G3 7LN

David J Goldberg,

deputy director

MRC Medical

Sociology Unit

University of

Glasgow, Glasgow

G12 8RZ

assistant director 